\title{
Identifikasi Minyak Kedelai yang Ditambahkan dalam Produk Minyak Zaitun dengan Metode Kromatografi Gas-Spektroskopi Massa
}

\author{
Identification of Soybean Oil Added to Olive Oil Products by Gas \\ Chromatography-Mass Spectroscopy Method
}

\author{
Purwaniati*, Zuhroul Fauziatul Umri, Winasih Rachmawati \\ RUBI Analisis Farmasi dan Kimia Medisinal, Fakultas Farmasi, Universitas Bhakti Kencana Bandung \\ Jl. Soekarno - Hatta 754 Bandung
}

Kontak : purwaniati@bku.ac.id

\begin{abstract}
ABSTRAK
Buah zaitun dikenal sebagai tanaman rempah yang memiliki nilai jual yang tinggi di pasar dunia karena kandungan asam lemaknya yang bermanfaat untuk tubuh. Produk minyak zaitun dapat dikonsumsi secara langsung. Mahalnya harga minyak zaitun murni menyebabkan adanya adulterasi minyak zaitun dengan jenis minyak nabati lainnya, seperti minyak kedelai. Penelitian ini bertujuan untuk menentukan kemurnian minyak zaitun dan mengidentifikasi penambahan minyak kedelai pada produk minyak zaitun dipasaran. Penelitian ini dilakukan dalam beberapa tahapan, meliputi preparasi sampel, ekstraksi buah zaitun dengan metode konvensional dan ekstraksi biji kedelai dengan sokletasi, serta analisis komponen minyak zaitun murni dan minyak zaitun yang dicampur dengan minyak kedelai dengan metode kromatografi gas - spektroskopi massa (KGSM). Hasil analisis persen susut pengeringan dan rendemen buah zaitun berturut-turut sebesar $2,14 \%$ dan $97,85 \%$. Sedangkan persen susut pengeringan dan rendemen biji kedelai berturut-turut sebesar 0,79\% dan 99,20\%. Hasil analisis dengan metode KGSM menunjukan bahwa minyak zaitun dan minyak zaitun yang dicampur dengan minyak kedelai memberikan rasio asam linoleate/oleat (rasio 1/o) yang berbeda. Minyak zaitun murni mempunyai kandungan asam linoleat yang jauh lebih kecil dibandingkan asam oleatnya (rasio 1/o =0,0703) sebaliknya, minyak kedelai mengandung asam linoleate yang jauh lebih besar daripada asam oleatnya (rasio 1/o = 1,3029). Rasio 1/o tersebut dapat digunakan untuk menilai kemurnian minyak zaitun. Dari tiga sampel produk minyak zaitun yang diuji, hanya 1 sampel yang memiliki rasio 1/o seperti pada minyak zaitun murni.
\end{abstract}

Kata Kunci : minyak zaitun,adulterasi, kemurnian minyak zaitun, kromatografi gas-spektroskopi massa

\begin{abstract}
Olive fruit is known as a spice plant that has a high selling value on the world market because of its fatty acid content which is beneficial for the body. Olive oil products can be consumed directly. The high price of pure olive oil causes the adulteration of olive oil with other types of vegetable oils, such as soybean oil. The aims of the research is to determine the purity of olive oil and identify the addition of soybean oil to olive oil products in the market. This research was carried out in several stages, including sample preparation, olive extraction with conventional methods and soybean seed extraction with soxhletation, as well as component analysis of pure olive oil and olive oil mixed with soybean oil by gas chromatography-mass spectroscopy (GC-MS) methods. The results of the analysis of drying losses and yield percentages of olive were $2.14 \%$ and $97.85 \%$, respectively. While the drying losses and yield percentages of soybean seed were $0.79 \%$ and $99.20 \%$, respectively. The results of the analysis using the GC-MS method show that olive oil and olive oil mixed with soybean oil give different linoleate / oleic acid ratios (l/o ratio). Pure olive oil has a smaller linoleic acid content than its oleic acid (ratio $/ / o=0.0703$ ) in contrast, soybean oil contains linoleic acid which is much greater than its oleic acid (ratio $/ / o=1.3029$ ). The l/o ratio can be used to assess the purity of olive oil. Of the three samples of olive oil products tested, only 1 sample had l/o ratio as in pure olive oil.
\end{abstract}

Keywords: olive oil, adulteration, olive oil purity, gas chromatography-mass spectroscopy 


\section{PENDAHULUAN}

Produk minyak zaitun mulai banyak diketahui manfaatnya oleh masyarakat. Termasuk di wilayah Jawa Barat yang masyarakatnya juga menggunakan produk minyak zaitun sebagai penunjang pola hidup sehat. Cara pemanfatan produk minyak zaitun mulai dari perawatan kecantikan sampai kesehatan. Sebagai perawatan kecantikan biasa digunakan untuk perawatan kulit dan rambut. Sedangkan sebagai kesehatan biasa digunakan untuk memasak atau untuk pembuatan salad, bahkan ada pula yang dikonsumsi secara langsung. Minyak zaitun banyak digunakan sebagai bahan makanan (digunakan baik untuk menggoreng atau dikonsumsi bersama salad), kosmetik, dan industri farmasi (Chiapetta A, 2012).

Zaitun dikenal sebagai salah satu tanaman buah yang banyak (>750 juta pohon zaitun) dibudidayakan di seluruh dunia. Sekitar $99 \%$ dari total produksi zaitun di dunia merupakan milik negara di seluruh cekungan Mediterania dan Timur Tengah. Menurut Food and Agriculture Organization (FAO) pada tahun 2009, lahan seluas 9,9 juta hektar (ha) di daerah mediterania ditanami dengan pohonpohon zaitun. Spanyol merupakan produsen terbesar minyak zaitun dengan total luas 2.500.000 ha untuk pembudidayaan zaitun diikuti oleh Italia (1.159.000 ha) dan Yunani (765.000 ha) (Ghanbari et al. 2012).

Berdasarkan jenisnya, minyak zaitun dapat dibedakan menjadi lima jenis. (1) ExtraVirgin Olive Oil yang dihasilkan dari perasan pertama dan memiliki tingkat keasaman kurang dari 1 persen. Dianjurkan untuk kesehatan dan dapat diminum secara langsung. (2) Virgin Olive Oil, hampir menyerupai extra virgin olive oil, Bedanya, virgin olive oil diambil dari buah yang lebih matang dan punya tingkat keasaman lebih tinggi. (3) Refined Olive Oil, merupakan minyak zaitun yang berasal dari hasil penyulingan. Jenis ini tingkat keasamannya lebih dari 3,3 persen. Aromanya kurang begitu baik dan rasanya kurang menggugah lidah. (4) Pure Olive Oil, merupakan minyak zaitun paling banyak dijual di pasaran. Warna, aroma, dan rasanya lebih ringan daripada virgin olive oil. (5) Extra Light Olive Oil, jenis ini merupakan campuran minyak zaitun murni dan hasil sulingan, sehingga kualitasnya kurang begitu baik. Namun, jenis ini cukup populer karena harganya lebih murah daripada jenis lainnya.

Minyak zaitun telah dikenal memiliki banyak kegunaan, sebagaimana yang diungkapkan dalam berbagai penelitian. Komponen fenolik dalam minyak zaitun berperan menurunkan resiko aterosklerosis, penyakit kardiovaskuler, penyakit neurodegeneratif dan beberapa tipe kanker. Minyak zaitun merupakan komponen penting dalam diet Mediterania (Cicerale et al. 2009; Cicerale, Lucas, and Keast 2010). Kandungan polifenol berfungsi dalam memperbaiki fungsi kolesterol HDL, menurunkan tekanan darah dan memperbaiki fungsi endothelial (Hernáez et al. 2014; Moreno-Luna et al. 
2012). Selain itu, extra virgine olive oil mempunyai komponen-komponen minor yang terbukti memperbaiki kondisi penyakitpenyakit yang berkaitan dengan sistem imun dan inflamasi, seperti: rheumatoid artritis, lupus eritematosus sistemik dan sklerosis (Aparicio-Soto et al. 2016). Kandungan fenolik dalam minyak zaitun juga memiliki efek antioksidan. Senyawa utama fenolik tersebut adalah hidroksitirosol and oleuropein (Tripoli et al. 2005).

Minyak zaitun mengandung $72 \%$ asam oleat yang merupakan asam lemak tak jenuh tunggal (Waterman and Lockwood 2007). Hal tersebut merupakan keistimewaan minyak zaitun sebab kebanyakan minyak hasil olahan biji lainnya terdiri dari asam lemak tak jenuh ganda. Jika dibandingkan dengan asam lemak tak jenuh ganda, contohnya asam linoleat, asam oleat yang memiliki satu ikatan rangkap, tidak mudah teroksidasi sehingga dapat bertindak sebagai antioksidan, memiliki stabilitas lebih tinggi, masa penyimpanan yang baik, serta berperan penting dalam pencegahan kanker (Bartolini et al. 2005; Méndez and Falqué 2007). Asam oleat berperan penting dalam mencegah perkembangan sel kanker karena berperan dalam menginduksi apoptosis dan diferensiasi sel (Waterman and Lockwood 2007).

Harga minyak zaitun murni yang relatif mahal, menyebabkan beberapa produsen menambahkan minyak jenis lain dengan tujuan menambah volume dan meningkatkan keuntungan (adulterasi). Berdasarkan uraian yang telah disebutkan di atas, maka penulis bermaksud melakukan analisis secara kromatografi gas-spektroskopi massa minyak kedelai yang ditambahkan pada produk minyak zaitun. Selain itu juga untuk menggambarkan profil asam lemak produk minyak zaitun yang ditambahkan minyak kedelai.

\section{METODE PENELITIAN}

\section{Alat dan bahan}

Alat-alat yang digunakan dalam penelitian ini adalah satu unit alat Kromatografi Gas Spektrometri Massa atau KGSM yang dilengkapi detektor ionisasi nyala, kolom kapiler, fase diam, gas pembawa, pemroses data, integrator, mycrosyringe, sentrifugator, vortex, tabung reaksi tahan panas bertutup teflon, mikro pipet, stirer, hot plate, termometer dan alat-alat gelas yang umum digunakan dalam analisa kuantitatif. Kromatografi gas yang digunakan adalah Agilent Technologies 7890A yang digabungkan dengan alat Spektroskopi Massa dengan merek Agilent Technologies 5975C dan dilengkapi dengan Agilent Technologies 7693 Autosampler yang merupakan alat injeksi otomatis yang diperoleh melalui komputer

Bahan-bahan yang digunakan dalam penelitian ini terdiri dari produk minyak zaitun yang diperoleh dari berbagai wilayah di Jawa Barat, biji kedelai, boron tri fluorida (BF3), n-heksan, metanol, $\mathrm{NaOH}$, dan air suling. 


\section{Ekstraksi Buah Zaitun}

Buah zaitun dibuat pasta dengan cara dipisahkan dari bijinya, kemudian dihaluskan dan disaring dengan menggunakan kain saring. Cairan yang dihasilkan disaring lagi menggunakan kertas saring. Proses penyaringan dilakukan selama 24 jam pada kondisi wadah tertutup gelap, sehingga terbentuk dua lapisan, kemudian diambil bagian paling atas untuk dipisahkan kedalam botol vial. minyak zaitun yang diperoleh disimpan dalam botol vial berwarna coklat.

\section{Ekstraksi Biji Kedelai}

Sejumlah biji kedelai ditumbuk untuk mendapatkan ukuran yang lebih kecil dari biji kedelai. Hasilnya dibungkus dengan kertas saring, kemudian dimasukkan dalam alat sokletasi. Pelarut n-heksan dimasukkan ke dalam labu alas bulat beserta batu didih secukupnya. Ekstraksi dengan sokletasi selama 120 menit.

\section{Penetapan Susut Pengeringan dan Rendemen Ekstrak}

Terhadap ekstrak yang dihasilkan dilakukan penetapan susut pengeringan dan rendemen ekstrak. Persen rendemen ditentukan dengan menimbang biji zaitun atau kedelai yang akan diekstraksi ( $\left.\mathrm{B}_{\text {sampel }}\right)$ dan ekstrak zaitun atau kedelai yang dihasilkan ( $\left.\mathrm{B}_{\text {ekstrak}}\right)$. Rendemen kemudian dihitung dengan persamaan berikut:

$$
\text { Rendemen }(\%)=\frac{B_{\text {sampel }}}{B_{\text {ekstrak }}} \times 100 \%
$$

Penentuan susut pengeringan dilakukan dengan menimbang seluruh ekstrak yang dihasilkan (berat awal atau B0) kemudian mengeringkan ekstrak tersebut hingga diperoleh serbuk kering (berat akhir atau B1). Persen susut pengeringan (SP) dihitung dengan persamaan:

$$
S P(\%)=\frac{B 0-B 1}{B 0} \times 100 \%
$$

\section{Saponifikasi Sampel Minyak}

Dilakukan proses saponifikasi terhadap hasil ekstrak minyak yang diperoleh melalui penambahan $\mathrm{NaOH} 0,5 \mathrm{~N}$ sebanyak $6 \mathrm{~mL}$. Kemudian dilakukan pemanasan selama 10 menit pada suhu $50^{\circ} \mathrm{C}$ menggunakan bantuan magnetic stirrer, setelah beberapa saat pada bagian lapisan atas dipisahkan untuk dilakukan proses derivatisasi.

\section{Derivatisasi Sampel Minyak}

Dipipet sebanyak 1,0 mL sampel minyak hasil saponifikasi dimasukkan ke dalam botol vial dan direaksikan dengan boron tri fluorida (BF3) dalam metanol sebanyak $1 \mathrm{~mL}$. Kemudian diaduk menggunakan stirerr dan dipanaskan pada suhu $50^{\circ} \mathrm{C}$ selama \pm 15 menit. Selanjutnya didiamkan sampai terbentuk 2 lapisan. Dilakukan sentrifugasi dan tampung lapisan atas yang mengandung metil asam lemak. Hasil esterifikasi dimasukkan ke dalam vial untuk dianalisis lebih lanjut dengan KGSM.

\section{Analisis Komponen Minyak}

Analisis komponen minyak dilakukan menggunakan Kromatografi Gas- 
Spektrometri Massa (KGSM). Masingmasing sampel minyak hasil dari serangkaian proses kemudian diinjeksikan pada alat KGSM. Hasil injeksi minyak terdeteksi dalam bentuk peak yang mempunyai waktu retensi yang berbeda. Perbedaan waktu retensi dari tiap senyawa disebabkan oleh perbedaan pemisahan komponen karena perbedaan interaksi tiap senyawa dengan kolom dan suhu yang digunakan. Setiap puncak dari kromatogram yang dihasilkan diidentifikasi luas areanya dari masing-masing senyawa asam lemak yang terdeteksi. Kemudian fragmen massa yang dihasilkan dari spektrometri dibandingkan dengan fragmen masa dari senyawa yang telah diketahui menggunakan data Library KGSM.

\section{HASIL DAN PEMBAHASAN}

Minyak zaitun yang digunakan sebagai standar dalam penelitian ini diperoleh dengan cara pemerasan, dimana dari $500 \mathrm{~g}$ buah zaitun diperoleh $15 \mathrm{~mL}$ minyak zaitun. Minyak kedelai diperoleh dengan cara sokletasi. Persen susut pengeringan dan

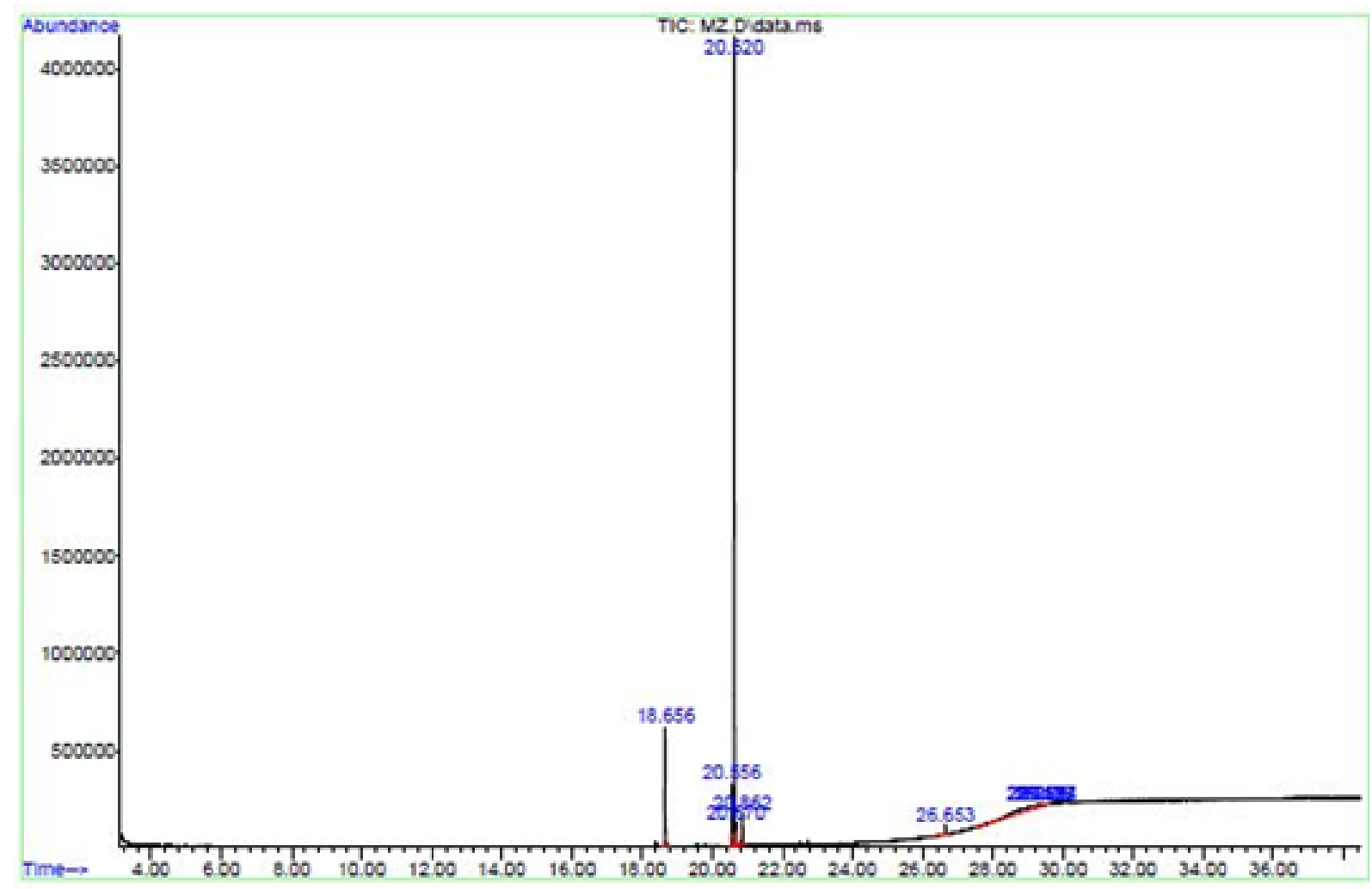

Gambar 1. Kromatogram minyak zaitun standar

Tabel 1. Asam lemak dengan intensitas paling besar dalam minyak zaitun standar

\begin{tabular}{cccccccc}
\hline No & Puncak & $\begin{array}{c}\text { WR } \\
(\mathrm{menit})\end{array}$ & $\begin{array}{c}\text { Senyawa Asam } \\
\text { Lemak }\end{array}$ & $\begin{array}{c}\text { Jenis Asam } \\
\text { Lemak }\end{array}$ & $\begin{array}{c}\text { SNI } \\
(\%)\end{array}$ & Area & $\begin{array}{c}\text { Area } \\
(\%)\end{array}$ \\
\hline 1 & 6 & 18,405 & Asam Palmitoleat & MUFA & $0,3-3,5$ & 382732 & 0,418 \\
2 & 7 & 18.656 & Asam Palmitat & SFA & $7,5-20,0$ & 10079170 & 11,013 \\
3 & 10 & 20.556 & Asam Linoleat & PUFA & $3,5-21,0$ & 4772212 & 5,215 \\
4 & 11 & 20.619 & Asam Oleat & MUFA & $55,0-83,0$ & 67873377 & 74,165 \\
5 & 43 & 20.862 & Asam Stearat & SFA & $0,5-5,0$ & 2622725 & 2,866 \\
\hline \multicolumn{7}{l}{ WR $=$ Waktu Retensi }
\end{tabular}


rendemen ekstraknya masing-masing sebesar $2,14 \%$ dan $97,85 \%$ pada buah zaitun, sedangkan untuk biji kedelai masing-masing sebesar $0,79 \%$ dan $99,20 \%$.

Proses saponikasi terhadap asam lemak dengan $\mathrm{NaOH}$ akan membentuk garam natrium asam lemak yang kemudian diderivatisasi untuk membentuk metil asam salisilat (senyawa ester) yang lebih mudah menguap sehingga dapat dianalisis dengan KGSM.

Dari hasil analisis dengan KGSM, diketahui bahwa minyak zaitun mengandung 43 senyawa asam lemak yang ditandai dengan adanya 43 puncak kromatogram (Gambar 1). Dari 43 senyawa asam lemak dalam minyak zaitun, terdapat 5 senyawa yang menunjukan intensitas paling tinggi yaitu asam oleat, palmitat, linoleat, stearat dan palmitoleat, data lengkap dapat dilihat pada Tabel 1.

Minyak kedelai teridentifikasi mengandung 19 asam lemak yang dibuktikan dengan adanya 19 puncak pada kromatogram (Gambar 2), dan 5 asam lemak dengan

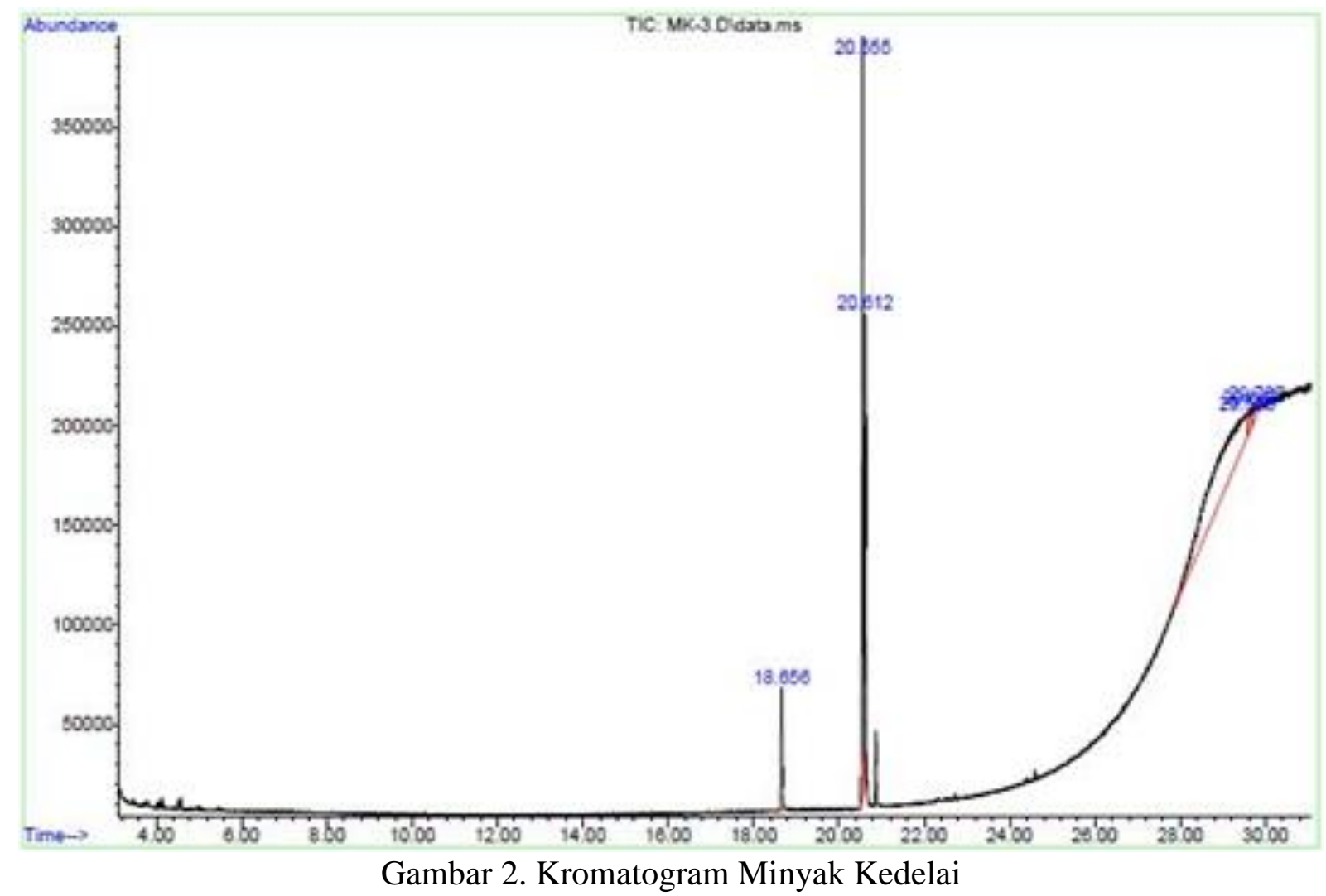

Tabel 2. Senyawa asam lemak dengan intensitas terbesar pada minyak kedelai

\begin{tabular}{ccccccc}
\hline No & Puncak & $\begin{array}{c}\text { WR } \\
(\text { menit })\end{array}$ & $\begin{array}{c}\text { Senyawa Asam } \\
\text { Lemak }\end{array}$ & $\begin{array}{c}\text { Jenis Asam } \\
\text { Lemak }\end{array}$ & Area & Area (\%) \\
\hline 1 & 3 & 4,577 & Asam Palmitolenat & PUFA & 104970 & 0,718 \\
2 & 4 & 18,656 & Asam Palmitat & SFA & 1199055 & 8,204 \\
3 & 5 & 20,556 & Asam Linoleat & PUFA & 6408948 & 43,850 \\
4 & 6 & 20,619 & Asam Oleat & MUFA & 4919007 & 33,656 \\
5 & 7 & 20,862 & Asam Stearat & SFA & 731300 & 5,004 \\
\hline
\end{tabular}


intensitas paling besar berturut-turut: asam linoleat, oleat, palmitat, stearat dan palmitolenat, data lengkap dapat dilihat pada Tabel 2.

Asam lemak minyak zaitun sangat didominasi oleh asam oleat, sedangkan asam lemak minyak kedelai didominasi minyak linoleat. Pencampuran minyak kedelai ke dalam minyak zaitun merubah profil asam lemak dan minyak zaitun tersebut (Tabel 3). Minyak zaitun murni mempunyai rasio linoleate-oleat (1/o) sebesar 0,0703, sedangkan minyak kedelai murni mempunyai rasio 1/o sebesar 1,3029. Penambahan minyak kedelai ke dalam minyak zaitun menyebabkan peningkatan rasio 1/o meningkat. Semakin

Tabel.3 Profil Asam Lemak Campuran Minyak Zaitun dan Minyak Kedelai (50:50)

\begin{tabular}{cccccccc}
\hline No & Puncak & $\begin{array}{c}\text { WR } \\
(\text { menit })\end{array}$ & $\begin{array}{c}\text { Senyawa Asam } \\
\text { Lemak }\end{array}$ & $\begin{array}{c}\text { Jenis Asam } \\
\text { Lemak }\end{array}$ & $\begin{array}{c}\text { SNI } \\
(\%)\end{array}$ & Area & $\begin{array}{c}\text { Area } \\
(\%)\end{array}$ \\
\hline 1 & 10 & 18,405 & Asam Palmitoleat & MUFA & $0,3-3,5$ & 706747 & 0,344 \\
2 & 11 & 18,656 & Asam Palmitat & SFA & $7,5-20,0$ & 11511729 & 11,198 \\
3 & 14 & 20,556 & Asam Linoleat & PUFA & $3,5-21,0$ & 4193760 & 17,283 \\
4 & 15 & 20,619 & Asam Oleat & MUFA & $55,0-83,0$ & 54535076 & 64,401 \\
5 & 16 & 20,862 & Asam Stearat & SFA & $0,5-5,0$ & 2168959 & 3,731 \\
\hline
\end{tabular}

$\mathrm{WR}=$ Waktu Retensi

Tabel 4. Profil Asam Lemak Produk Minyak Zaitun 1

\begin{tabular}{cccccccc}
\hline No & Puncak & $\begin{array}{c}\text { WR } \\
(\text { menit })\end{array}$ & $\begin{array}{c}\text { Senyawa Asam } \\
\text { Lemak }\end{array}$ & $\begin{array}{c}\text { Jenis Asam } \\
\text { Lemak }\end{array}$ & $\begin{array}{c}\text { SNI } \\
(\%)\end{array}$ & Area & $\begin{array}{c}\text { Area } \\
(\%)\end{array}$ \\
\hline 1 & 5 & 18,405 & Asam Palmitoleat & MUFA & $0,3-3,5$ & 2500595 & 0.993 \\
2 & 6 & 18,656 & Asam Palmitat & SFA & $7,5-20,0$ & 35683202 & 14.172 \\
3 & 10 & 20,556 & Asam Linoleat & PUFA & $3,5-21,0$ & 18727287 & 7.438 \\
4 & 11 & 20,619 & Asam Oleat & MUFA & $55,0-83,0$ & 175673092 & 69.770 \\
5 & 12 & 20,862 & Asam Stearat & SFA & $0,5-5,0$ & 9013291 & 3.580 \\
\hline
\end{tabular}

Tabel 5. Profil Asam Lemak Produk Minyak Zaitun 2

\begin{tabular}{cccccccc}
\hline No & Puncak & $\begin{array}{c}\text { WR } \\
(\text { menit })\end{array}$ & $\begin{array}{c}\text { Senyawa Asam } \\
\text { Lemak }\end{array}$ & $\begin{array}{c}\text { Jenis Asam } \\
\text { Lemak }\end{array}$ & $\begin{array}{c}\text { SNI } \\
(\%)\end{array}$ & Area & $\begin{array}{c}\text { Area } \\
(\%)\end{array}$ \\
\hline 1 & 6 & 18,405 & Asam Palmitoleat & MUFA & $0,3-3,5$ & 4370738 & 1.459 \\
2 & 7 & 18,656 & Asam Palmitat & SFA & $7,5-20,0$ & 48991949 & 16.358 \\
3 & 11 & 20,556 & Asam Linoleat & PUFA & $3,5-21,0$ & 50230831 & 16.772 \\
4 & 12 & 20,619 & Asam Oleat & MUFA & $55,0-83,0$ & 181083647 & 60.464 \\
5 & 13 & 20,862 & Asam Stearat & SFA & $0,5-5,0$ & 10095911 & 3.371 \\
\hline
\end{tabular}

Tabel 6. Profil Asam Lemak Produk Minyak Zaitun 3

\begin{tabular}{|c|c|c|c|c|c|c|c|}
\hline No & Puncak & $\begin{array}{c}\text { WR } \\
\text { (menit) }\end{array}$ & $\begin{array}{c}\text { Senyawa Asam } \\
\text { Lemak }\end{array}$ & $\begin{array}{c}\text { Jenis Asam } \\
\text { Lemak }\end{array}$ & $\begin{array}{l}\text { SNI } \\
(\%)\end{array}$ & Area & $\begin{array}{c}\text { Area } \\
(\%)\end{array}$ \\
\hline 1 & 5 & 18,405 & Asam Palmitoleat & MUFA & $0,3-3,5$ & 706747 & 0.910 \\
\hline 2 & 6 & 18,656 & Asam Palmitat & SFA & $7,5-20,0$ & 11511729 & 14.814 \\
\hline 3 & 9 & 20,556 & Asam Linoleat & PUFA & $3,5-21,0$ & 4193760 & 5.397 \\
\hline 4 & 10 & 20,619 & Asam Oleat & MUFA & $55,0-83,0$ & 54535076 & 70.180 \\
\hline 5 & 12 & 20,862 & Asam Stearat & SFA & $0,5-5,0$ & 2168959 & 2.791 \\
\hline
\end{tabular}


besar penambahan minyak kedelai kedalam produk minyak zaitun akan menyebabkan peningkatan rasio 1/o yang semakin besar. Campuran minyak zaitun dan kedelai (50:50) menyebabkan rasio 1/o meningkat hingga 0,2683 .

Hasil analisis profil asam lemak terhadap 3 sampel produk minyak zaitun yang dijual di daerah Kota Bandung diperoleh nilai rasio 1/o masing-masing sampel yaitu: 0,1066;0,2773 dan 0,0763. Dari ketiga sampel tersebut maka dapat dinyatakan bahwa sampel 3 dengan rasio 1/o 0,0763 merupakan minyak zaitun yang paling mendekati murni. Sedangkan sampel 1 dan 2 dapat diduga diadulterasi dengan minyak kedelai. Profil asam lemak sampel produk minyak zaitun dapat dilihat pada Tabel 4,5 dan 6.

\section{KESIMPULAN}

Dari hasil penelitian ini maka dapat disimpulkan bahwa penambahan minyak kedelai ke dalam produk minyak zaitun dapat dideteksi dengan metode kromatografi gasspektroskopi massa. Produk minyak zaitun yang diadulterasi dengan minyak kedelai akan menunjukan rasio 1/o yang lebih besar daripada minyak zaitun murni. Minyak zaitun murni memiliki nilai rasio 1/o 0,0703.

\section{DAFTAR PUSTAKA}

Aparicio-Soto, Marina et al. 2016. "Extra
Virgin Olive Oil: A Key Functional Food for Prevention of Immune-Inflammatory Diseases." Food and Function.

Bartolini et al. 2005. "Olive Germplasm: Cultivars and World-Wide Collections." FAO. Roma.

Cicerale, Sara, Xavier A. Conlan, Andrew J. Sinclair, and Russell S.J. Keast. 2009. "Chemistry and Health of Olive Oil Phenolics." Critical Reviews in Food Science and Nutrition.

Cicerale, Sara, Lisa Lucas, and Russell Keast. 2010. "Biological Activities of Phenolic Compounds Present in Virgin Olive Oil." International Journal of Molecular Sciences.

Ghanbari, Rahele et al. 2012. "Valuable Nutrients and Functional Bioactives in Different Parts of Olive (Olea Europaea L.)-A Review." International Journal of Molecular Sciences.

Hernáez, Álvaro et al. 2014. "Olive Oil Polyphenols Enhance High-Density Lipoprotein Function in Humans: A Randomized Controlled Trial." Arteriosclerosis, Thrombosis, and Vascular Biology.

Méndez, Ana Isabel, and Elena Falqué. 2007. "Effect of Storage Time and Container Type on the Quality of Extra-Virgin Olive Oil." Food Control.

Moreno-Luna, Rafael et al. 2012. "Olive Oil Polyphenols Decrease Blood Pressure and Improve Endothelial Function in Young Women with Mild Hypertension." American Journal of Hypertension.

Tripoli, Elisa et al. 2005. "The Phenolic Compounds of Olive Oil: Structure, Biological Activity and Beneficial Effects on Human Health." Nutrition Research Reviews.

Waterman, Emily, and Brian Lockwood. 2007. "Active Components and Clinical Applications of Olive Oil." Alternative Medicine Review. 